\title{
Metáforas situadas em charges sobre economia: multimodalidade e argumentação
}

Métaphores situées dans des dessins sur l'économie: multimodalité et argumentation

\section{llana Souto de Medeiros}

Universidade Federal do Rio Grande do Norte - UFRN - Rio Grande do Norte- Brasil

Resumo: Este artigo tem como principal objetivo evidenciar que as metáforas, enquanto mecanismos cognitivos, estão presentes nos mais diversos modos de comunicação, o que lhes confere um caráter multimodal e, muitas vezes, argumentativo. Para isso, propomos um breve panorama teórico acerca da metáfora, apresentando, de modo breve, a Teoria da Metáfora Conceptual (LAKOFF; JOHNSON, 1980 [2002]); damos ênfase, principalmente, à noção de metáfora situada (VEREZA, 2013, 2016), que, em linhas gerais, são licenciadas pelas metáforas conceptuais; e analisamos três charges sobre a economia, que foram extraídas com o auxílio da ferramenta de busca Google. Nossa análise mostrou que as metáforas situadas construídas a partir das charges possuem uma natureza argumentativa, o que permite delimitar visões de mundo bastante específicas.

Palavras-chave: Metáforas. Metáforas situadas. Multimodalidade. Argumentação.

Résumé: Le principal objectif de cet article est de démontrer que les métaphores, en tant que mécanisme cognitif, sont presentes dans plusieurs formes de communication, ce que leur donne un caractère multimodal et, souvent, argumentatif. Pour cela, on propose un bref aperçu théorique par rapport à la métaphore, en présentant, de façon brève, la Théorie de la Métaphore Conceptuelle (LAKOFF; JOHNSON, 1980 [2002]); on met en relief, surtout, la notion de métaphore située (VEREZA, 2013, 2016), que, d'une façon générale, sont licenciées par les métaphores conceptuelles; et on analyse trois dessins sur l'économie, qui ont été extraits à l'aide de l'outil de recherche Google. Notre analyse a montré que les métaphores situées construites sur les dessins possèdent une nature argumentative, ce qui permet de délimiter des visions de monde assez spécifiques.

Mots-clés: Métaphores. Métaphores situées. Multimodalité. Argumentation. 


\section{Introdução}

Este artigo se insere nos estudos contemporâneos da metáfora, uma vez que utiliza corpus autêntico para buscar evidenciar que as metáforas são mecanismos cognitivos e não apenas uma figura exclusiva da dimensão linguística, uma vez que podem ser construídas a partir dos mais diversos modos de comunicação.

Nesse sentido, propomos um breve panorama teórico acerca dos estudos da metáfora, dando ênfase, principalmente, à Teoria da Metáfora Conceptual (TMC), construída por Lakoff e Johnson (1980, [2002]), e à noção de "metáfora situada", proposta por Vereza (2013, 2016), que nos fornece, além de outras contribuições, indícios de um caráter argumentativo associado à metáfora.

Todos esses trabalhos, é válido destacar, são fundamentados a partir da ideia de corporalidade, que se refere ao fato de que nossas experiências sensório-motoras subjazem o processo de construção da linguagem e dos sentidos, ou, como sugerem Duque e Costa, às habilidades cognitivocomunicacionais do indivíduo, que "[...] são interpretadas como fenômenos resultantes de sua existência como sistemas físicos em contínua interação com seu ambiente [...]" (2012, p. 8).

Em termos metodológicos, nossa pesquisa é de cunho qualitativo. Por meio de nossas análises, buscamos evidenciar que as metáforas podem ser construídas a partir de textos multimodais e que elas apresentam um teor argumentativo, ou seja, nossa investigação se volta para um fenômeno específico, sem a necessidade de recorrermos, por exemplo, à quantificação de valores. Para alcançar tais objetivos, analisamos três charges referentes à economia, que foram extraídas com o auxílio da ferramenta de busca Google.

\section{Breve histórico acerca das metáforas}

Os estudos sobre as metáforas delimitaram, ao longo dos tempos, dois paradigmas bem definidos. No primeiro deles, que podemos definir como "paradigma tradicional", as metáforas são compreendidas como uma figura exclusivamente linguística, cuja função, grosso modo, é a de estilizar o discurso.

Esse paradigma, que data do século IV a.C, tem como principal precursor Aristóteles. Nos seus escritos sobre poesia, o filósofo sugere que uma linguagem nobre ou elevada seria aquela que faz uso de metáforas. A partir dessa ideia, tornou-se comum associar as metáforas a um artifício de embelezamento do discurso, normalmente utilizado por poetas.

Embora essa compreensão pareça ter sido adotada como verdade absoluta pelo senso comum, e frequentemente atribuída ao filósofo, é necessário levar em conta que Aristóteles também sugere ter reconhecido que a metáfora pode ser considerada um elemento basilar à linguagem cotidiana. Isso fica evidente em seus escritos sobre a retórica, sobretudo a partir da seguinte afirmação:

O termo próprio, o vocábulo usual e a metáfora são as únicas expressões úteis para o estilo do discurso puro e simples. O que confirma é que elas são as únicas a serem utilizadas por toda a gente; não há ninguém que na conversação corrente não se sirva de metáforas [...] (ARISTÓTELES, 1959, p. 193 [grifo nosso]).

Mesmo reconhecendo as metáforas como um mecanismo natural, e não como algo exclusivamente estilístico, a visão associada à poética, como mencionamos, foi fortemente difundida durante séculos, sendo questionada, apenas, a partir do final da década de 1970.

Tais questionamentos marcaram a construção de um novo paradigma, aqui definido como o "paradigma de ruptura". Em sua base fundante, verificamos que o lócus da metáfora migra da dimensão linguística para a do pensamento.

O delinear dessa nova perspectiva se iniciou com a publicação, em 1979, do artigo The Conduit Metaphor (Metáfora do Canal), de Michael Reddy. Nesse trabalho, o autor mostrou que a comunicação é conceptualizada como um processo de transmissão de ideias, mostrando, assim, que as metáforas não são exclusivas da linguagem, já que parecem fazer parte de nosso sistema conceptual. 
A consolidação desse paradigma, contudo, foi dada por George Lakoff e Mark Johnson, com a publicação, em 1980, da obra Metaphors we live by (Metáforas da Vida Cotidiana). Nesse trabalho, os autores propõem a TMC, cuja principal premissa se apoia na ideia de que as metáforas resultam de um mapeamento - ou correspondências conceptuais entre um domínio fonte, de base mais experiencial, e um domínio alvo, de natureza menos experiencial.

Um dos exemplos clássicos que ilustra essa proposta, a metáfora conceptual AMOR É UMA VIAGEM $^{1}$, pode ser encontrada no artigo The Contemporany Theory of Metaphor (LAKOFF, 1992). A partir do enunciado "our relationship has hit a deadend street” (idem, p. 4), por nós traduzido como "nosso relacionamento chegou em um beco sem saída", Lakoff chama a atenção para o fato de que a metáfora emergente da relação entre esses indexadores linguísticos apresenta um conjunto de correspondências ontológicas que caracterizam um mapeamento, como se observa na Figura 1.

DOMÍNIO ALVO - AMOR

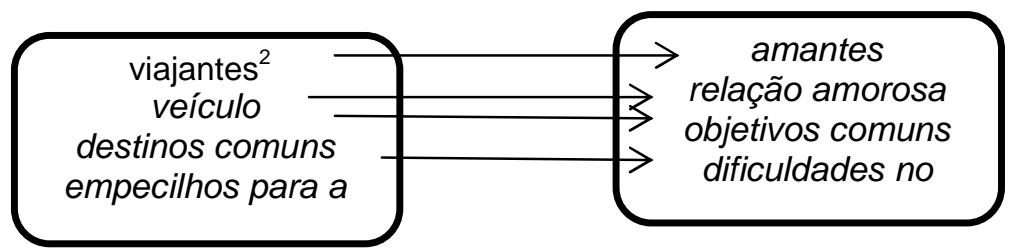

Figura 1. Mapeamento metafórico da metáfora conceptual AMOR É UMA VIAGEM.

A Figura 1 mostra as correspondências que são feitas entre os componentes do domínio VIAGEM, que pode ser considerado de base mais experiencial, e do domínio AMOR, de natureza menos física. Por meio do enunciado supracitado, podemos inferir que os viajantes correspondem aos amantes, o veículo à relação amorosa, os destinos comuns da viagem aos objetivos comuns do casal, e os eventuais empecilhos às dificuldades que surgem no relacionamento. Dessa forma, os elementos mais próximos de nossas experiências físicas, quando projetados, tornam o domínio alvo, AMOR, "menos abstrato".

\footnotetext{
${ }^{1}$ Utilizamos versalete, fonte 9 , para nos referirmos às metáforas conceptuais e/ou a conceitos e domínios.

${ }^{2}$ Componentes de um domínio, assim como as metáforas situadas, são grafados em itálico.
}

Apesar das inúmeras contribuições trazidas pela TMC, no que concerne, sobretudo, à compreensão de que as metáforas são mecanismos inerentes de nosso sistema conceptual, o trabalho de Lakoff e Johnson sofreu diversas críticas. Uma das mais apontadas, conforme nos lembra Vereza (2013), diz respeito à utilização de "exemplos inventados" para confirmar a existência de determinadas metáforas conceptuais.

A autora questiona, no entanto, a viabilidade dessa crítica, pois os exemplos dados pelo linguista e pelo filósofo são, segundo ela, "[...] frutos da experiência dos autores como membros legítimos da comunidade discursiva de falantes de língua inglesa" (VEREZA, 2013, p. 3).

Ainda de acordo com Vereza, essas críticas levaram muitos estudiosos da metáfora a utilizar, em suas pesquisas, corpora autênticos. Nesse "paradigma contemporâneo" encontramos, além dessa característica, estudos da metáfora relacionados ao processo de construção dos sentidos, à semelhança do que propomos neste artigo.

Uma vez que usamos charges para subsidiar nossas análises, estamos investigando o discurso online, ou seja, a metáfora em uso, e não apenas as pertencentes a nosso sistema conceptual. Nesse sentido, é de fundamental importância tecer discussões sobre a noção de "metáfora situada", que será apresentada a seguir.

\section{Metáforas situadas}

Enquanto as metáforas conceptuais são caracterizadas, de forma resumida, como mecanismos pertencentes a nosso sistema conceptual, ou seja, estruturas estáveis, tais quais os Modelos Cognitivos Idealizados - MCls (LAKOFF, 1987), as metáforas situadas, propostas por Vereza (2013), são de natureza deliberada e, "[...] mesmo não sendo sempre textualmente explicitadas (na forma $x$ é $y$ ) conferem coerência e unidade cognitiva do discurso online" (idem, p. 10).

A fim de tornar mais clara tal distinção, Vereza (2016) sugere que nossa cognição pode ser compreendida a partir de dois níveis. O primeiro 
deles, que seria o nível estável, corresponde ao sistema conceptual e seria composto por representações mentais mais estáveis, como as metáforas conceptuais, os $\mathrm{MCls,} \mathrm{os} \mathrm{esquemas}$ imagéticos, etc. Já o segundo, chamado de nível episódico, está relacionado, mais diretamente, à linguagem em uso. Nele, instâncias do nível estável podem ser recrutadas para licenciar estruturas episódicas que participam de uma tessitura textual online. Por essa razão, a autora afirma que a separação entre os níveis se dá apenas por questões analíticas, tendo em vista que ambos mantêm uma relação de simbiose.

Ainda de acordo com Vereza (2016), é de extrema importância compreender, em pesquisas cujo foco de análise é a linguagem metafórica, a distinção entre metáforas conceptuais e situadas, pois isso implica "[...] questões sobre a convencionalidade, a disseminação sociocognitiva e discursiva e o grau de deliberalidade e/ou consciência no uso da metáfora" (idem p. 568). Outro aspecto que merece ser destacado diz respeito ao fato de que, embora seja comum identificar metáforas conceptuais subjacentes às situadas, há casos em que isso não ocorre, o que fortalece sua natureza deliberada e, até mesmo, criativa.

Outra característica observada nas metáforas situadas, segundo a autora, é seu teor potencialmente argumentativo. Ao analisar essas metáforas em memes, Vereza (2013) constatou que a articulação entre as dimensões estável e episódica influencia a produção de sentidos, assim como contribui para o desenvolvimento da argumentação.

Para ilustrarmos uma ocorrência desse tipo de metáfora, extraímos, com o auxílio do Google, uma notícia relacionada à economia brasileira, da qual destacamos o trecho "A BM\&FBOVESPA é o coração da Economia brasileira, são seus batimentos que determinam a nossa saúde financeira $^{3 "}$ (grifos nossos). Por meio dos itens destacados, sobretudo "coração" e "batimentos" é possível perceber que a economia é vista como algo

3 A notícia completa está disponível em: $<$ https://br.blastingnews.com/economia/2016/12/ha-segurancana-bolsa-de-valores-brasileira-001349127.html>. Acesso em: 01 out. 2018. que tem coração, indexado, textualmente, por "BM\&FBOVESPA". A articulação entre esses itens nos permite inferir a metáfora situada BM\&FBOVESPA é coração e verificar o mapeamento que é construído online: o componente órgão essencial, pertencente ao domínio CORAÇÃO, é recrutado e projetado para 0 domínio alvo BM\&FBOVESPA, como mostra a figura 2.

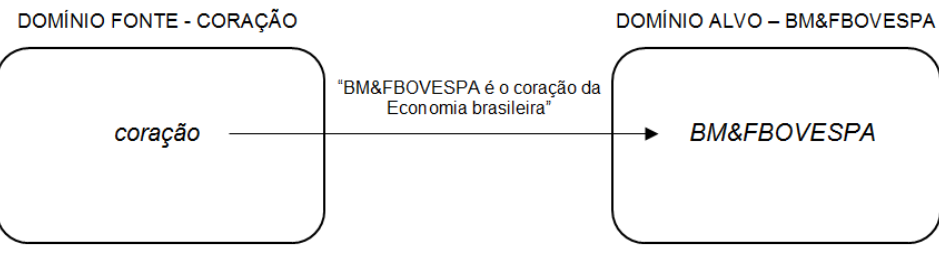

Figura 2. Projeção entre domínios que licencia a metáfora situada BM\&FBOVESPA é coração.

Figura 2. Projeção entre domínios que licencia a metáfora situada BM\&FBOVESPA é coração.

Essa metáfora situada, que se ancora na metáfora conceptual ECONOMIA É ORGANISMO, apresenta uma natureza argumentativa, pois expressa a tese de que bolsa de valores brasileira (BM\&FBOVESPA) é um órgão essencial e determinante para a manutenção da saúde financeira do país, assim como o é um coração para um organismo.

$\mathrm{Na}$ seção seguinte, mostraremos outras ocorrências de metáforas situadas associadas ao discurso econômico. Como já mencionado, nosso corpus é constituído por charges. Digitamos as palavras "charge" e "economia" no Google e, na aba de imagens, selecionamos os três exemplares que serão discutidos a seguir.

Cumpre ressaltar que nosso principal objetivo é o de analisar as metáforas situadas que podem ser construídas a partir das charges. Nesse sentido, não serão levados em conta, em nossas análises, aspectos de natureza política, embora tenhamos consciência de seus impactos no nível do discurso.

\section{Análise: metáforas situadas em charges sobre economia}

Nesta seção apresentamos a análise das três charges selecionadas com o auxílio do Google. Em cada uma delas, mostramos qual a metáfora situada 
emergente, assim como a argumentação por ela tecida. A primeira charge está ilustrada na Figura 3.

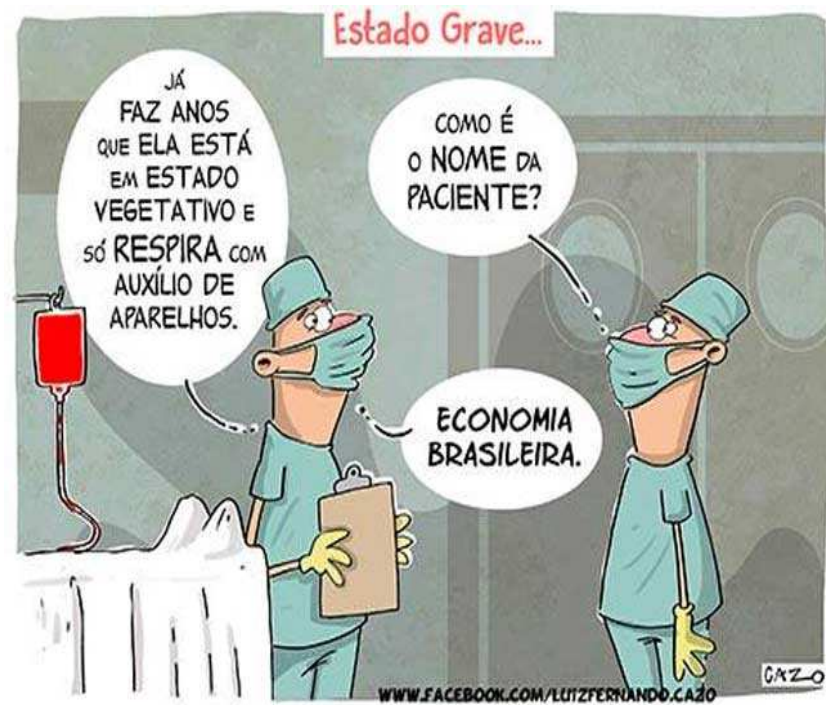

Figura 3. Charge $^{4}$ sobre a economia brasileira.

Percebemos, na figura 3 , que a articulação entre recursos linguísticos e visuais constrói sentidos bastante específicos. As expressões "ela está em estado vegetativo", "só respira com auxílio de aparelhos" e "estado grave", evocam a ideia de um organismo cuja saúde está bastante comprometida. Esse organismo, por sua vez, é explicitado na charge por meio dos itens "paciente" e "economia brasileira". Esses sentidos, como é possível observar, são reforçados pelos recursos visuais utilizados na charge, como os dois médicos, aparentemente em uma Unidade de Terapia Intensiva (UTI), o paciente na maca, e a bolsa para coleta de sangue, que sugere uma provável transfusão.

Da relação entre esses recursos, inferimos a emergência da metáfora situada economia é um paciente em estado grave, que é licenciada pela metáfora conceptual ECONOMIA É ORGANISMO e construída a partir articulação que se estabelece entre três domínios, como ilustra a figura 4.

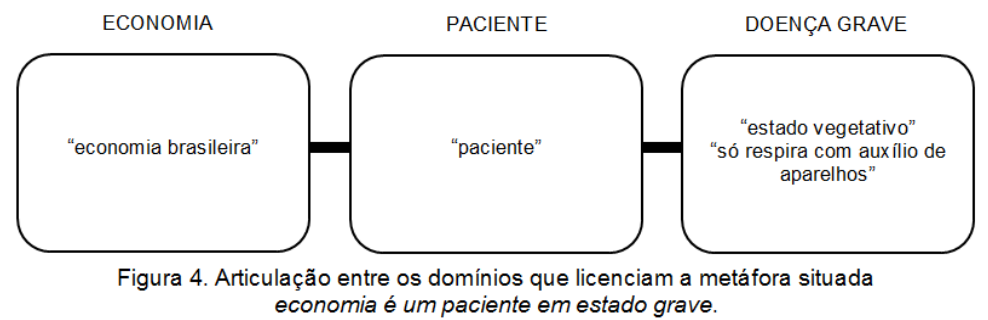

Figura 4. Articulação entre os domínios que licenciam a metáfora situada economia é um paciente em estado grave.

Observamos, na figura 4, a existência de três domínios, cada um acionado por seus respectivos itens linguísticos: o domínio ECONOMIA, indexado por "economia brasileira", o domínio PACIENTE, instanciado por "paciente", e o domínio DOENÇA GRAVE, evocado pelos itens "estado vegetativo" e "só respira com auxílio de aparelhos".

Diferentemente do que ocorre com as metáforas conceptuais, licenciadas pela projeção entre dois domínios, verificamos que essa metáfora situada é construída pela interação entre três domínios. A nosso ver, o domínio fonte pode ser considerado o PACIENTE, enquanto que o alvo, a ECONOMIA. O terceiro domínio, DOENÇA GRAVE, parece ter sido recrutado para potencializar o teor argumentativo da metáfora situada emergente, ou seja, a economia não está apenas doente, mas em estado crítico - tese apresentada pela charge.

$\mathrm{Na}$ charge que analisaremos a seguir identificamos uma metáfora situada que, assim como a primeira, também parece ser licenciada pela metáfora conceptual ECONOMIA É ORGANISMO.

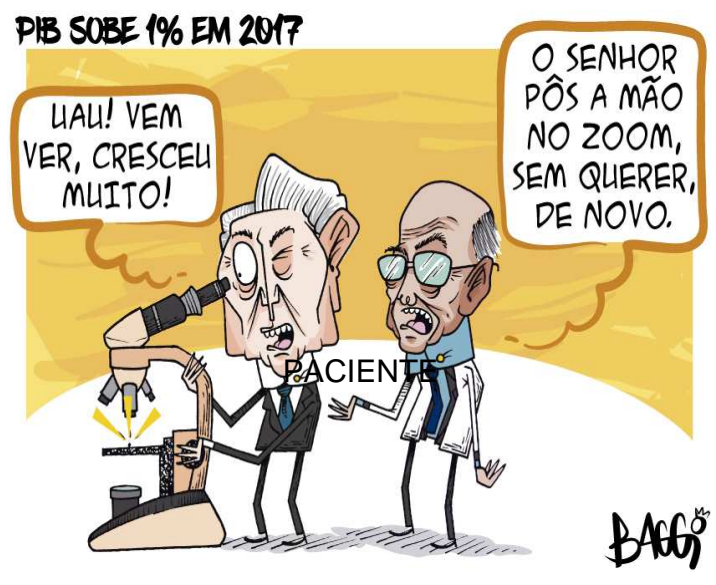

Figura 5. Charge ${ }^{5}$ sobre o PIB.

\footnotetext{
${ }^{5}$ Disponível em: <http://www.dmtemdebate.com.br/os-desafios-

${ }^{5}$ Disponível em: <http://www.dmtemdebate.com.br/os-desafios-
da-economia-brasileira-entrevista-com-ricardo-carneiro/>. Acesso em: 01 out. 2018.
}

\footnotetext{
${ }^{4}$ Disponívelem:<http://paduacampos.com.br/2012/2016/01/25/p onto-de-vista-projecoes-da-economia-para-este-ano-tambemsao-sinistras/charge-economia-brasileira-2/>. Acesso em: 01 out. 2018.
} 
Por meio da charge ilustrada na figura 5 notamos, graças aos recursos linguísticos e visuais, que o domínio da economia é evocado metonimicamente por "PIB". Os sentidos emergentes, como se observa, são construídos de modo irônico, pois o personagem da esquerda faz referência a um "alto crescimento" do PIB, enquanto que, na verdade, ele só é capaz de enxergá-lo com o auxílio de um microscópio - o que corrobora a pequena elevação (1\%) do PIB em 2017. Isso nos leva a perceber, assim a construção da metáfora situada PIB é um microrganismo.

Essa metáfora, assim como foi constatado na primeira charge analisada, resulta da interação entre três domínios. No entanto, apenas um deles é linguisticamente indexado, como se verifica na figura 6.

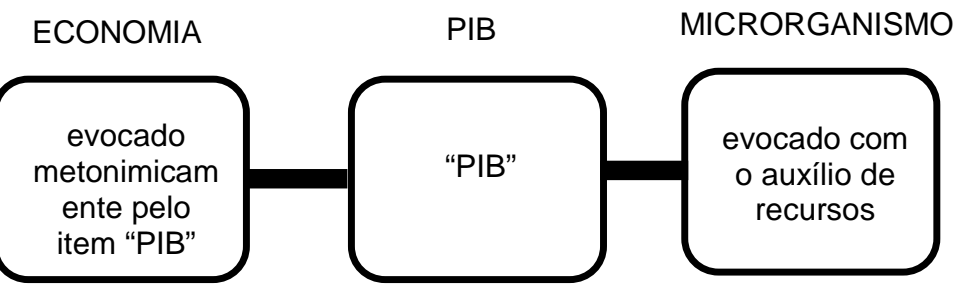

Figura 6. Articulação entre os domínios que licenciam a metáfora situada PIB é um microrganismo.

Percebemos, na figura 6, que a metáfora situada PIB é microrganismo emerge da relação entre os domínios ECONOMIA, PIB e MICRORGANISMO. O primeiro deles, ECONOMIA, embora não esteja linguisticamente explícito, pode ser evocado, por metonímia, pelo item "PIB", o mesmo que aciona o segundo domínio: PIB. O terceiro, que também não está indexado por itens linguísticos, é recuperado com o auxílio dos recursos visuais presentes na charge, mais especificamente a imagem do microscópio, que representa o instrumento com capacidade de ampliar elementos bastante pequenos e imperceptíveis para a visão humana. Este último, assim como observado na charge anterior, confere à metáfora situada PIB é um microrganismo um teor potencialmente argumentativo, uma vez que reforça a tese de que o crescimento do PIB, em 2017, foi mínimo.

A articulação entre esses domínios também nos permite identificar, além da argumentação, uma crítica sendo construída. A admiração do personagem ao acreditar, vendo no microscópio, que o PIB cresceu, confronta a tese que realmente parece ser apresentada. Além disso, a constatação do ilusório crescimento ("Uau! Vem ver, cresceu muito!") provoca humor, pois a falsa impressão do primeiro personagem é rebatida pela fala do segundo: "O senhor pôs a mão no zoom, sem querer, de novo."

A última charge que será analisada, ilustrada na figura 7, apresenta uma natureza bastante criativa, pois, diferentemente das duas primeiras, não parece ter sido licenciada, diretamente, por nenhuma metáfora conceptual.

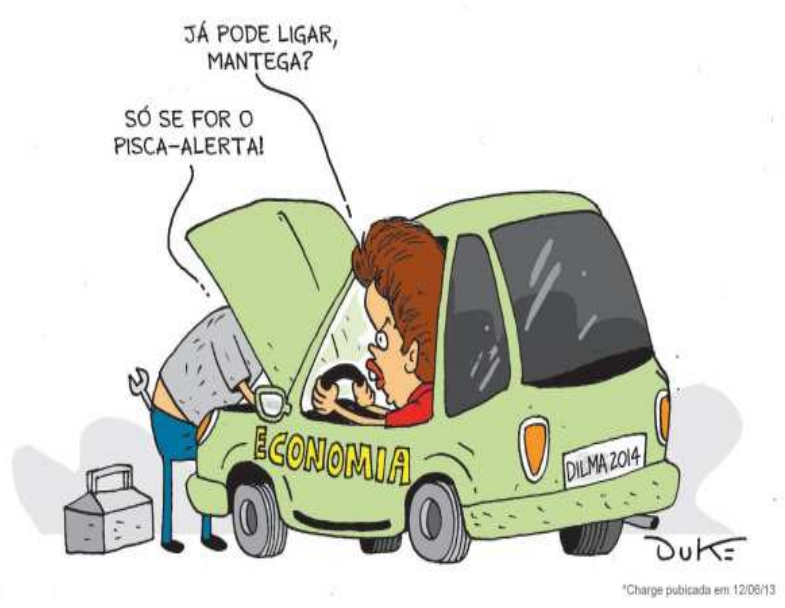

Figura 7. Charge ${ }^{6}$ sobre economia.

Os recursos visuais e linguísticos disponíveis nessa charge constroem sentidos bastante específicos. A imagem de um veículo sendo examinado por um mecânico nos faz perceber que o carro ilustrado na figura 7 está quebrado ou apresenta algum defeito que o impede de se movimentar. Esse carro, ainda de acordo com a figura, é representado pela economia, mais especificamente a economia brasileira, uma vez que a placa do veículo faz referência a um dos presidentes que já governaram o país.

Por meio dessas primeiras constatações, é possível inferir que a metáfora situada construída na charge é economia brasileira é um carro quebrado. Esta, como mostra a figura 8, emerge da interação entre três domínios.

\footnotetext{
${ }^{6}$ Disponível em: <https://www.otempo.com.br/charges/chargeo-tempo-18-01-1.775370>. Acesso em: 01 out. 2018.
} 


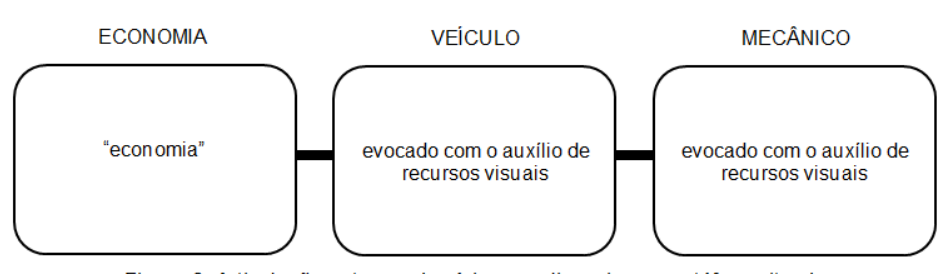

Figura 8. Articulação entre os domínios que licenciam a metáfora situada economia brasileira é um carro quebrado.

Figura 8. Articulação entre os domínios que licenciam a metáfora situada economia brasileira é um carro quebrado.

Dos três domínios evocados para viabilizar a construção dessa metáfora, conforme a figura 8, apenas um é indexado por recursos linguísticos: ECONOMIA. Os demais podem ser evocados com o auxílio dos recursos visuais disponíveis na charge: o domínio VEÍCULO, por meio da imagem de um carro, e o domínio MECÂNICO, graças à imagem do personagem, que, com suas ferramentas, procura identificar qual o problema que fez com que o "carro da economia" parasse de funcionar.

Assim como observado nas charges analisadas anteriormente, o terceiro domínio que participa da construção da metáfora situada economia brasileira é um carro quebrado potencializa a argumentação que dela emerge. Dito de outro modo, a projeção entre os domínios ECONOMIA e VEÍCULO não seria suficiente para defender a tese de que a situação econômica do país não é favorável. Nesse sentido, o domínio MECÂNICO parece ser utilizado para reforçar tal argumento, pois o trabalho de um mecânico, em grande parte, é o de consertar veículos quebrados ou com defeitos.

Outro aspecto que reforça esse argumento pode ser observado nas falas dos personagens: "Já pode ligar, Mantega?" e "Só se for o pisca-alerta!" (grifo nosso), sobretudo na do mecânico. O item pisca-alerta faz referência, no domínio VEÍCULO, ao instrumento utilizado para acionar uma luz vermelha que pisca nas lanternas dos carros. Este, por sua vez, é comumente usado em momentos de emergência e/ou como um sinal de alerta para situações de perigo. Esse elemento, quando recrutado e projetado para o domínio ECONOMIA, fortalece o argumento de que a economia brasileira, além de estar "quebrada", se encontra em uma situação de risco.

\section{Considerações finais}

Buscamos evidenciar, com o suporte teórico que subsidiou as análises desenvolvidas neste texto, que as metáforas, uma vez compreendidas como mecanismos próprios da cognição humana, podem emergir a partir das mais diversas formas de comunicação.

Por meio de textos multimodais, como charges associadas ao discurso econômico, constatamos a construção de metáforas situadas licenciadas, ou não, por metáforas conceptuais. Mostramos, também, que os recursos visuais disponíveis são de extrema importância para o refinamento dos sentidos evocados por essas metáforas.

Isso ficou constatado, por exemplo, ao verificarmos que as imagens ilustradas fortaleceram a argumentação subjacente às metáforas situadas construídas em cada charge. Sem elas, dificilmente os sentidos pretendidos seriam tão facilmente acessados.

Outro aspecto referente aos recursos visuais, que auxiliaram a viabilizar as metáforas situadas analisadas, diz respeito à crítica e/ou ao humor que eles provocam, como observado na charge em que a imagem do microscópio foi utilizada para fazer referência ao ínfimo crescimento do PIB no ano de 2017 - de apenas 1\%.

A partir dessas breves considerações, ressaltamos a importância dos estudos da metáfora em uso, sobretudo as que são construídas a partir da linguagem multimodal. Esperamos, com este texto, incitar pesquisadores a desenvolver novos estudos, a partir dos quais a dinamicidade das metáforas seja cada vez mais corroborada. 


\section{Referências}

ARISTÓTELES. Arte retórica e Arte poética. Tradução de Antônio Pinto de Carvalho. São Paulo: Difusão Europeia do livro, 1959.

DUQUE, P. H.; COSTA, M. A. Linguística Cognitiva: em busca de uma arquitetura de linguagem compatível com modelos de armazenamento e categorização de experiências. Natal, RN: EDUFRN, 2012.

LAKOFF, G. Women, Fire and Dangerous Things: what categories reveal about the mind. University of Chicago Press, 1987.

\begin{tabular}{c} 
The Contemporany Theory of Metaphor. \\
\hline Disponível
\end{tabular} https://terpconnect.umd.edu/ israel/lakoff-

ConTheorMetaphor.pdf>. Acesso em: 02 out. 2018.

LAKOFF, G.; JOHNSON, M. Metaphors we live by. University of Chicago Press, 1980.

Metáforas da vida cotidiana. Tradução de Mara Zanotto. Campinas: Mercadão das letras, 2002.

REDDY, M. J. The conduit metaphor: a case of frame conflict in our language about language. Disponível em: <https://msu.edu/ orourk51/800Phil/Handouts/Readings/Linguistics/Reddy-

TheConduitMetaphor-1979.pdf>. Acesso em: 02 out. 2018.

VEREZA, S. C. "Metáfora é que nem...": cognição e discurso na metáfora situada. Signo, Santa Cruz do Sul, v. 38, n. 65, p. 2-21, jul. dez. 2013.

Cognição e sociedade: um olhar sob a óptica da linguística cognitiva. Linguagem em (Dis)curso - LemD, Tubarão, SC, v. 16, n. 3, p. 561-573, set. dez. 2016.

\section{COMO CITAR ESSE ARTIGO}

MEDEIROS, Ilana Souto. Metáforas situadas em charges sobre economia: multimodalidade e argumentação. Signo, Santa Cruz do Sul, v. 44, n. 79, jan. 2019. ISSN 1982-2014. Disponível em: <https://online.unisc.br/seer/index.php/signo/article/view/12696>. Acesso em:

doi: https://doi.org/10.17058/signo.v44i79.12696. 